\title{
Maternal Transfer of Cuticular Hydrocarbons? Evidence from Between-Species Cross-Fostering Experiments in Earwigs
}

\author{
Stefan Boos ${ }^{1}$ • Lilian Röllin ${ }^{1}$ • Janine W. Y. Wong ${ }^{1}$ • \\ Mathias Kölliker ${ }^{1}$
}

Accepted: 7 April 2015 /

Published online: 21 April 2015

(C) Springer Science+Business Media New York 2015

\begin{abstract}
When females care for broods of mixed paternity, there is a threat of enhanced rivalry among offspring of different paternal lineages. This competition is against the best evolutionary interest of the female because she is equally related to all of her offspring and enhanced offspring competition would decrease her fitness. It was hypothesized earlier that mothers should therefore conceal the information about paternal origin in the recognition cues used by her offspring, for example by transferring the chemical cues used by her offspring for kin recognition. Here, we used a crossfostering experiment between two closely related and sympatric earwig species, Forficula auricularia and $F$. decipiens, to demonstrate that $F$. auricularia nymphs tended by $F$. decipiens females differ in their cuticular hydrocarbon profiles from $F$. auricularia nymphs tended by $F$. auricularia females. This result provides evidence for maternal transfer of cuticular hydrocarbons and shows that offspring adoption across species is possible in earwigs.
\end{abstract}

Keywords Kin recognition - social behaviour - maternal transfer - parental care dermaptera $\cdot$ Forficula auricularia $\cdot$ Forficula decipiens

\section{Introduction}

The rivalry among offspring forms part of the conflict between parents and their offspring over parental investment (Trivers 1974). The genetic relatedness among offspring thereby sets the limits of offspring selfishness favored by kin selection. When offspring are less related genetically, they should compete more intensely

Mathias Kölliker

Mathias.Koelliker@unibas.ch

1 Department of Environmental Sciences, Zoology and Evolution, University of Basel, Vesalgasse 1, 4051 Basel, Switzerland 
(Mock and Parker 1997). There are two main sources of variation in sibling relatedness in animal families that can exacerbate sibling rivalry: i) multiple paternity (or maternity) (Alonzo and Klug 2012; Wong et al. 2013), and ii) brood-mixing due to adoption or social parasitism (Wong and Kölliker 2013). In the former, siblings are related through the maternal (or paternal lineage), but unrelated through the paternal (or maternal) lineage. In the latter, the offspring from the caring parent are genetically unrelated to the adopted/invading nest mates. Despite clear prediction that parents should direct their costly care to own offspring, parents across taxa often care indiscriminately for own and foreign young (Keller 1997).

The extent to which variation in genetic relatedness can influence sibling rivalry depends on the availability of sufficiently reliable recognition cues. Because sibling rivalry can be against the best evolutionary interest of the caring parent (Mock and Parker 1997), the caring parent may have evolved means to conceal the information of recognition cues expressed in offspring. In the case of multiple paternity, for example, caring mothers may often have no interest in enhanced competition among offspring from different patrilines inside her clutch because she is equally related to all of her offspring, and she should hence prevent offspring recognition cues to express information about paternal origin (Wong et al. 2014b). In the case of adoption, maternal concealment of recognition cues in mixed broods may be favored if the mother experiences direct benefits of enlarged broods.

The broods of the European earwig Forficula auricularia are often sired by multiple males (Sandrin et al. 2015), and brood-mixing occurs when the mobile young (nymphs) leave their nest and join other families (Kölliker and Vancassel 2007; Wong and Kölliker 2013). Furthermore, earwig females seem to tolerate foreign eggs and nymphs and provide apparently indiscriminate maternal care to them (Kölliker and Vancassel 2007; Meunier and Kölliker 2012). Already Weyrauch (1927) observed that F. auricularia females did not discriminate between own and alien eggs during egg care, and in the sand earwig Labidura riparia it was shown that females accept foreign nymphs as long as the nymphs are located in the females' own nest (Radl and Linsenmair 1991). Thus, earwig mothers direct their care to eggs and nymphs from different sires, and towards own and unrelated offspring. While females show no obvious kin recognition, it was shown that nymphs are able to recognize nymphs from foreign broods which they kill and cannibalize earlier (Dobler and Kölliker 2010).

In insects, kin recognition is often mediated by cuticular hydrocarbons (CHCs) (Lihoreau and Rivault 2009; Blomquist and Bagnières 2010). In F. auricularia it was shown that the CHC-profiles did not contain information about the paternal origin during the nymph stage, and that this information was only revealed later during the adult stage of offspring (Wong et al. 2014b). Thus, during the stage when mothers care for nymphs, information about the paternal origin of nymphs is concealed in their CHC profiles, and it was hypothesized that mothers might actively apply $\mathrm{CHCs}$ through the grooming of nymphs to reduce sibling rivalry (Wong et al. 2014b).

In this study, we tested this hypothesis and the potential for maternal transfer of $\mathrm{CHC}$ recognition cues to nymphs by conducting a cross-fostering experiment between two closely related species of earwigs, Forficula auricularia and F. decipiens. We swapped eggs between females of the two species and investigated after a period of maternal egg care, if the composition of cuticular hydrocarbons on nymphs is qualitatively and quantitatively similar to the species of the foster mother or the species of the 
genetic mother. If maternal $\mathrm{CHC}$ transfer occurs, we predicted that the $\mathrm{CHC}$ profile of nymphs should be affected by the species of origin of the foster female.

\section{Materials \& Methods}

\section{Cross-Fostering Experiment}

The $F$. auricularia and $F$. decipiens females used in this experiment were from laboratory reared populations originally collected in the field in Dolcedo (Italy). The two species were caught in the same olive grove and from the same traps (for details see Meunier et al. 2012). The experiment was based on a total number of 20 clutches (Fig. 1). After oviposition, F. auricularia and F. decipiens females and F. auricularia eggs were randomly assigned to one of two treatments. Aa: F. auricularia females tending $F$. auricularia eggs/nymphs, Da: $F$. decipiens females tending $F$. auricularia eggs/nymphs. The eggs were swapped to foster females 4 days after oviposition and among females that had the same oviposition date. On day two and day 14 after hatching, nymphs were counted to quantify hatching success and nymph survival. Additionally, on day 6 after hatching, four nymphs of each clutch were selected haphazardly, introduced in a conical bottom autosampler vial (Agilent 5188-6591) and placed in the freezer at $-30{ }^{\circ} \mathrm{C}$ for later extraction of the nymphs' cuticular hydrocarbons (Wong et al. 2014a, b).

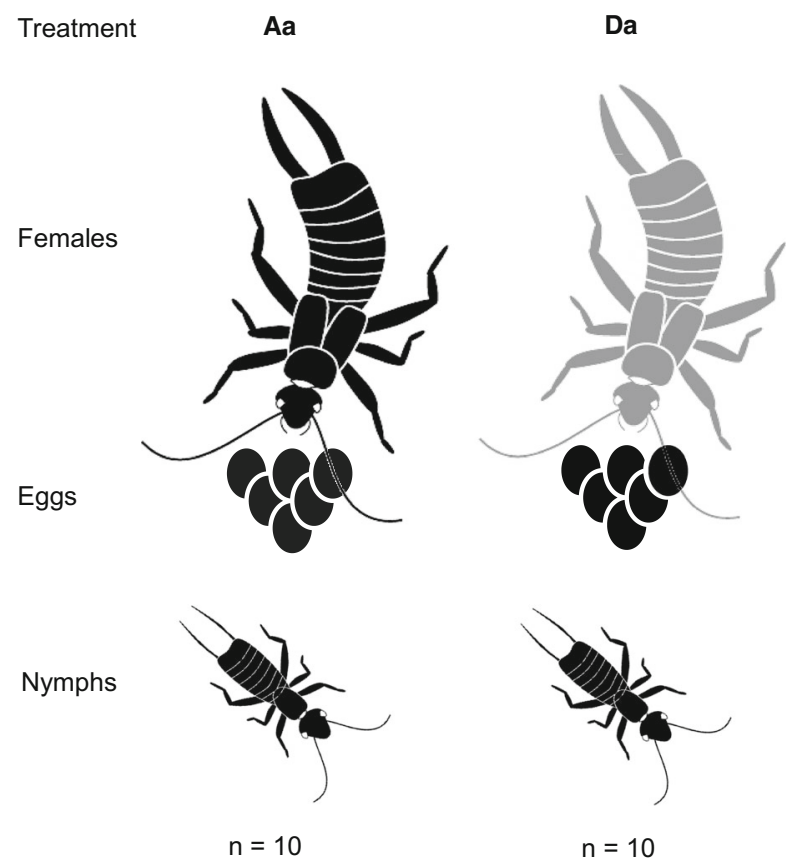

Fig. 1 Graphical illustration of the experimental design. The females were randomly assigned into one of two treatments. (Aa) F. auricularia females attend foreign $F$. auricularia offspring. (Da) $F$. decipiens females attend foreign $F$. auricularia offspring. $n$ refers to the number of replicates (i.e., sample size) per treatment. Black $=F$. auricularia, grey $=F$. decipiens 


\section{Cuticular Hydrocarbon Analysis}

The cuticular hydrocarbons were extracted from four haphazardly chosen nymphs per clutch in $100 \mu \mathrm{L}$ heptane $\left(\mathrm{C}_{7} \mathrm{H}_{16}\right.$, Merck, Zug, Switzerland) containing $2.5 \mathrm{ng} / \mu \mathrm{L}$ of internal standard (n-octadecane, $\mathrm{C}_{18} \mathrm{H}_{38}$, Sigma-Aldrich, Buchs, Switzerland) for the duration of $10 \mathrm{~min}$. Subsequently, $60 \mu \mathrm{L}$ of the extract were pipetted into an additional conical bottom autosampler vial. Chemical analysis was conducted with an Agilent7890 gas chromatograph (GC) coupled to an Agilent5975C inert XC MSD mass spectrometer (MS). Two $\mu \mathrm{l}$ of each sample were injected into the GC-MS using a splitless mode and a DB5 column (HP-5 ms: length: $30 \mathrm{~m}$, inner diameter: $0.25 \mathrm{~mm}$, film thickness: $0.25 \mu \mathrm{m}$, Agilent Technologies, Basel, Switzerland). The SSL injector temperature was held constant at $250{ }^{\circ} \mathrm{C}$ and a helium flow rate of $1 \mathrm{~mL} / \mathrm{s}$ over the whole duration of the $\mathrm{GC}$ run. GC oven temperature started at $70^{\circ} \mathrm{C}$, was initially held for $2 \mathrm{~min}$, then ramped at $15^{\circ} \mathrm{C} / \mathrm{min}$ to $232^{\circ} \mathrm{C}$ (where it was held for $11 \mathrm{~min}$ ), at $5^{\circ} \mathrm{C} / \mathrm{min}$ to $263{ }^{\circ} \mathrm{C}$ and $15{ }^{\circ} \mathrm{C} / \mathrm{min}$ to $300{ }^{\circ} \mathrm{C}$ (where it was held for $7 \mathrm{~min}$ ).

The chemical compounds were identified by comparing the mass spectra of the peaks with the mass spectral library NIST2008 and with former identifications of F. auricularia $\mathrm{CHC}$ profiles (Wong et al. 2014a, b).

\section{Statistical Analysis}

The statistical analyses were conducted using $\mathrm{R}$ (Version 3.0.3). We provide medians and median absolute deviation (MAD) as robust descriptive statistics and exact Wilcoxon's rank sum test for pair wise comparisons of $\mathrm{CHC}$ compound quantities between treatments ( $\mathrm{R}$ packages: coin and exactRankTest). Clutch sizes did not differ significantly between the Aa and Da treatment, with a mean $( \pm \mathrm{SD})$ clutch size in the Aa treatment of $23.83 \pm 0.98$ eggs and of $23.57 \pm 1.27$ in the Da treatment $\left(W_{\text {exact }}=23.5, P=0.788\right)$.

\section{Results}

There was no significance difference in the total amount of $\mathrm{CHCs}$ between $F$. auricularia nymphs tended either by $F$. auricularia or $F$. decipiens females ( $W_{\text {exact }}=29.00, P=0.295$ ). Conversely, there was a significant difference in the CHC profile composition between Aa and Da nymphs, as indicated by a significant global Kruskal-Wallis test $\left(\chi_{29}^{2}=164.92, P<0.0001\right)$. Five cuticular hydrocarbon peaks were significantly more abundant when the tending female was $F$. auricularia, and three peaks were significantly more abundant when the tending female was $F$. decipiens (Fig. 2 and Table 1).

Hatching success on day 2 was significantly higher in Da than Aa clutches $\left(n_{\mathrm{Aa}}=5\right.$, $n_{\mathrm{Da}}=5 ; W_{\text {exact }}=2.00, P=0.032$ ), but the number of nymphs on day 14 after hatching did not differ significantly $\left(n_{\mathrm{Aa}}=6, n_{\mathrm{Da}}=7 ; W_{\text {exact }}=20, P=0.916\right)$. There was a nonsignificant tendency for lower nymph survival between day two and day 14 in Da as compared to Aa clutches $\left(n_{\mathrm{Aa}}=5, n_{\mathrm{Da}}=5 ; W_{\text {exact }}=3.50, P=0.063\right)$. However, there were no significant correlations between the quantities of individual peaks and nymph survival $\left|r_{s}\right|<0.37$. 


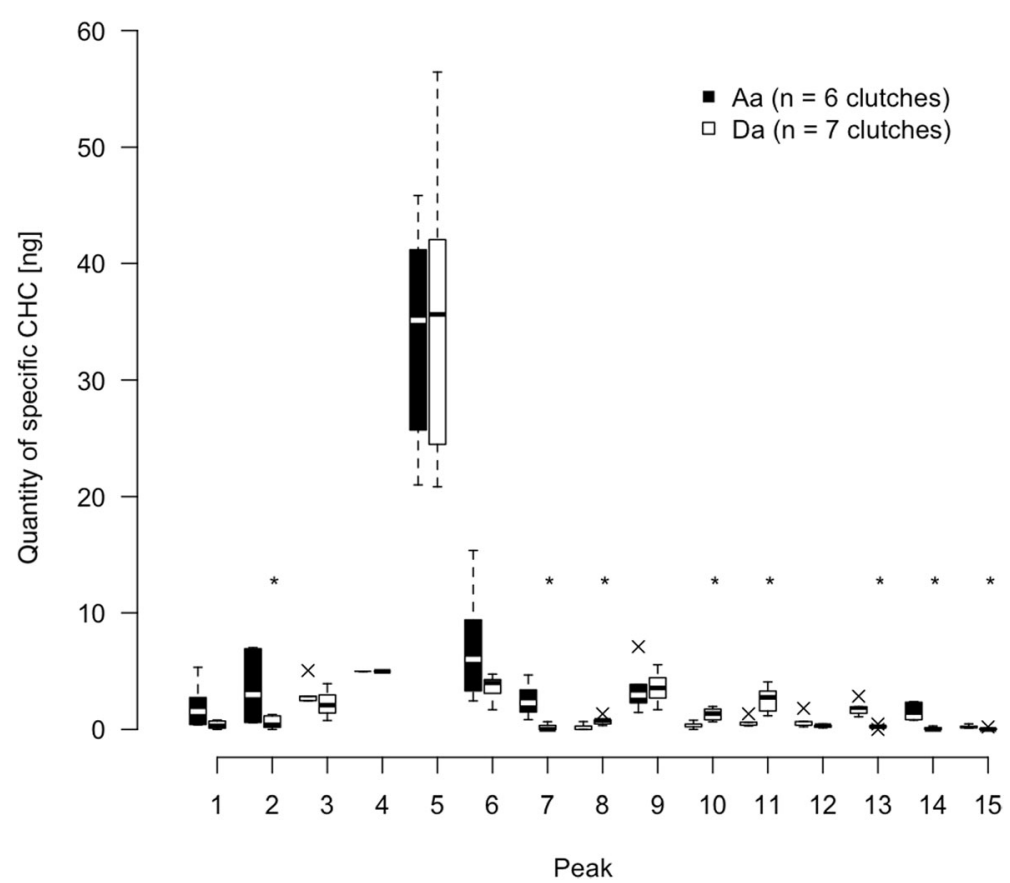

Fig. 2 Box-plots for the CHC profiles compared between the Aa and Da treatments. The y-axis shows the quantity of each $\mathrm{CHC}$ (ng). The $\mathrm{x}$-axis shows the $\mathrm{CHCs}$ in the order of their retention time. Black boxes are the CHCs of nymphs tended by F. auricularia females. White boxes are the CHCs from nymphs tended by F. decipiens females. Box-plot: the horizontal lines represent the medians, the box inter-quartile range, the whiskers $1.5 \times$ inter-quartile-range and the X's box-plot outliers. Asterisks highlight statistically significant differences between the Aa and Da treatment $\left({ }^{*} P<0.05\right.$; see Table 1 for exact $P$-values)

\section{Discussion}

This study showed in a cross-fostering experiment between two closely related earwig species, F. auricularia and F. decipiens, that the species-of-origin of the tending female significantly affected the composition of the hydrocarbon profile of the tended nymphs. Five peaks (partly containing a mix of several compounds) were more abundant when the tending mother was $F$. auricularia (2-ethyl-benzoquinone, $\mathrm{X}-, 5-\mathrm{MeC}_{25}$, 13-,11-,9-, 7-,5- $\mathrm{MeC}_{29}$, and two unknown $\mathrm{CHCs}$ ) and three compounds/mixtures were more abundant when the tending mother was $F$. decipiens $\left(3-\mathrm{MeC}_{25}+\mathrm{X}-\mathrm{nC}_{24: 1}\right.$, $13-, \mathrm{X}-, \mathrm{X}-\mathrm{MeC}_{26}$ and 11-,9-,7-,5-diMeC 26 ). These results are in line with the hypothesis that females transfer hydrocarbons onto the cuticle of their nymphs. However, the differences were quantitative in nature, and none of the CHC compounds were exclusive to one or the other female species. Thus, the results may also be explained by female $F$. auricularia and $F$. decipiens differing in their maternal behavior, which may affect nymph condition and in turn result in $\mathrm{CHC}$ profile differences between treatments due to differences in nymph condition. However, the compounds that showed differences between the Aa and Da treatment were not identical to those cuticular hydrocarbons affected by nymph condition (Mas et al. 2009). Furthermore, although hatching success and nymph survival differed between treatments, the compounds were not significantly correlated with hatching success and nymph survival. 
Table 1 Pair wise comparison of CHCs between the Aa and Da treatment

\begin{tabular}{|c|c|c|c|c|c|c|}
\hline Peak \# & R.T. [min] & Molecule-Name & $\begin{array}{l}\mathrm{CHC} \\
\text { Aa treatment } \\
\text { [ng] Median } \\
( \pm \mathrm{MAD})\end{array}$ & $\begin{array}{l}\text { CHC } \\
\text { Da treatment } \\
\text { [ng] Median } \\
( \pm \mathrm{MAD})\end{array}$ & $\begin{array}{l}\text { Test } \\
\text { statistic } \\
\mathrm{W}_{\text {exact }}\end{array}$ & $P$-value \\
\hline 1 & 5.21 & $\mathrm{C}_{7} \mathrm{H}_{6} \mathrm{O}_{2}$ (2-Methyl-Benzoquinone) & $1.54 \pm 1.68$ & $0.30 \pm 0.45$ & 33.0 & 0.097 \\
\hline 2 & 6.22 & $\mathrm{C}_{8} \mathrm{H}_{8} \mathrm{O}_{2}$ (2-Ethyl-Benzoquinone) & $2.99 \pm 3.56$ & $0.39 \pm 0.58$ & 36.0 & 0.034 \\
\hline 3 & 8.14 & $\mathrm{n}-\mathrm{C}_{13}$ (Tridecane) & $2.57 \pm 0.15$ & $2.09 \pm 1.32$ & 27.0 & 0.445 \\
\hline 4 & 12.24 & $\mathrm{n}-\mathrm{C}_{18}(\text { Octadecane })^{*}$ & $5.00 \pm 0.00$ & $5.00 \pm 0.00$ & 21.0 & 1.000 \\
\hline 5 & 20.64 & $\mathrm{C}_{25} \mathrm{H}_{50}$ (Z-12-Pentacosene $)$ & $35.14 \pm 11.47$ & $35.65 \pm 15.67$ & 22.0 & 0.945 \\
\hline 6 & 22.14 & $13-, 11-, 9-\mathrm{MeC}_{25}$ & $6.04 \pm 4.51$ & $4.01 \pm 0.49$ & 29.0 & 0.295 \\
\hline 7 & 22.35 & $\mathrm{X}-, 5-\mathrm{MeC}_{25}$ & $2.28 \pm 1.41$ & $0.00 \pm 0.00$ & 42.0 & 0.001 \\
\hline 8 & 22.63 & $3-\mathrm{MeC}_{25}+\left(\mathrm{X}-\mathrm{nC}_{24: 1}\right)$ & $0.10 \pm 0.15$ & $0.79 \pm 0.23$ & 3.0 & 0.008 \\
\hline 9 & 23.34 & Unknown & $2.95 \pm 1.18$ & $3.57 \pm 1.44$ & 17.0 & 0.628 \\
\hline 10 & 23.66 & $13-, \mathrm{X}-, \mathrm{X}-\mathrm{MeC}_{26}$ & $0.26 \pm 0.17$ & $1.37 \pm 0.81$ & 2.0 & 0.005 \\
\hline 11 & 24.55 & $11-, 9-, 7-, 5-\operatorname{diMeC}_{26}$ & $0.56 \pm 0.19$ & $2.76 \pm 1.45$ & 2.0 & 0.005 \\
\hline 12 & 25.41 & Unknown & $0.56 \pm 0.24$ & $0.33 \pm 0.13$ & 35.0 & 0.051 \\
\hline 13 & 31.73 & 13-, 11-, 9-, 7-, 5- $\mathrm{MeC}_{29}$ & $1.47 \pm 0.34$ & $0.24 \pm 0.11$ & 42.0 & 0.001 \\
\hline 14 & 32.04 & Unknown & $1.04 \pm 0.33$ & $0.00 \pm 0.00$ & 42.0 & 0.001 \\
\hline 15 & 32.44 & Unknown & $0.14 \pm 0.04$ & $0.00 \pm 0.00$ & 37.0 & 0.019 \\
\hline
\end{tabular}

All measured quantities are in ng (relative to internal standard)

R.T. Retention time

*Internal standard (Octadecane)

Finally, maternal CHC transfer to eggs (rather than nymphs) was previously and unambiguously shown in F. auricularia by extraction of glass-beads tended by females (Boos et al. 2014), and maternal grooming can be readily observed during the egg-stage and the first nymph instar (Mas and Kölliker 2011; Boos et al. 2014). Thus, our results on the effect of the species of origin of the tending female on nymph $\mathrm{CHC}$ profiles are best explained by maternal transfer.

But why should earwig females ultimately apply CHCs on their nymphs' cuticles? The hypothesis that the function of this behavior is to conceal information about genetic relatedness within a female's clutch is one of several mutually non-exclusive hypotheses (Wong et al. 2014b). Selection is expected to favor maternally determined kin recognition cues in particular in the case of multiple paternity, because it may prevent siblicide and cannibalism between a female's offspring that have different fathers (Wong et al. 2014b). Alternatively, the concealment of information about kinship may be a by-product of $\mathrm{CHC}$ transfer that has a different main function. For instance, CHCs may contribute to the protection of nymphs against microbial infection (in particular fungal infections; Herzner and Strohm 2007; Boos et al. 2014), or against desiccation (Blomquist and Bagnières 2010). But even in this latter case, in the presence of multiple paternity selection on females to prevent cannibalism inside her clutch may favour elevated transfer of CHCs beyond the level needed for the protective function alone. Further experiments are needed to fully determine the function(s) of maternal $\mathrm{CHC}$ transfer. 
All eggs and nymphs in the cross-fostering experiment were readily accepted by the females. The tolerance of foreign eggs and nymphs was known from earlier studies for within-species cross-fostering in F. auricularia (Meunier and Kölliker 2012; Wong and Kölliker 2013), but here we show that social tolerance of first instar nymphs by earwig females extends beyond species limits: $F$. decipiens females readily accepted and tended $F$. auricularia eggs and nymphs. Importantly, F. auricularia and F. decipiens co-occur in the same habitat in nature, and the individuals used in this experiment were progeny from animals from the two species caught in the same location in Dolcedo (Italy) and often in the same traps. Thus, encounters between species are common and there is scope for selection to enhance or reduce tolerance between them.

The observed social tolerance may partly be due to the qualitative similarity of the CHC profiles of $F$. auricularia and $F$. decipiens nymphs. Nevertheless, the profiles were not identical and differed systematically (this study) and, thus, contained chemical information about species origin that could be used by tending $F$. decipiens females to discriminate. It is conceivable that this quantitative variation is insufficient and outside the recognition abilities of earwig females and/or that the regular maternal grooming and $\mathrm{CHC}$ transfer may cover the species-specific profile too quickly. This scenario would imply that the maternal tolerance of nymphs across species-borders is nonadaptive for females, allowing nymphs to invade into nests and parasitize female care. Alternatively, females may be able to recognize the $\mathrm{CHC}$ profile differences but tolerate foreign nymphs due to direct benefits. It will be interesting to further investigate the degree to which earwig mothers show social tolerance to invasion by foreign nymphs from different species.

Acknowledgments We thank Joël Meunier for help during the experiment and comments on the manuscript. The study was financially supported by the Swiss National Science Foundation (grant-no. PP00P3139188 to Mathias Kölliker).

Conflicts of Interest The authors declare that they have no conflicts of interest.

\section{References}

Alonzo SH, Klug H (2012) Paternity, maternity and parental care. In: Royle NJ, Smiseth PT, Kölliker M (eds) The evolution of parental care. Oxford University Press, Oxford, pp 189-205

Blomquist GJ, Bagnières A-G (2010) Insect hydrocarbons. Cambridge University Press, Cambridge

Boos S, Meunier J, Pichon S, Kölliker M (2014) Maternal care provides antifungal protection to eggs in the European earwig. Behav Ecol 25:754-761

Dobler R, Kölliker M (2010) Kin-selected siblicide and cannibalism in the European earwig. Behav Ecol 21: 257-263

Herzner G, Strohm E (2007) Fighting fungi with physics: food wrapping by a solitary wasp prevents water condensation. Curr Biol 17:R46-R47

Keller L (1997) Indiscriminate altruism: unduly nice parents and siblings. Trends Ecol Evol 12:99-103

Kölliker M, Vancassel M (2007) Maternal attendance and the maintenance of family groups in common earwigs (Forficula auricularia): a field experiment. Ecol Entomol 32:24-27

Lihoreau M, Rivault C (2009) Kin recognition via cuticular hydrocarbons shapes cockroach social life. Behav Ecol 20:46-53

Mas F, Kölliker M (2011) Differential effects of offspring condition-dependent signals on maternal care regulation in the European earwig. Behav Ecol Sociobiol 65:341-349 
Mas F, Haynes KF, Kölliker M (2009) A chemical signal of offspring quality affects maternal care in a social insect. Proc R Soc Lond B 276:2847-2853

Meunier J, Kölliker M (2012) Parental antagonism and parent-offspring co-adaptation interact to shape family life. Proc R Soc Lond B 279:3981-3988

Meunier J, Wong JWY, Gomez Y, Kuttler S, Röllin L, Stucki D, Kölliker M (2012) One clutch or two clutches? Coexisting alternative female life-histories in the European earwig. Evol Ecol 26:669-682

Mock DW, Parker GA (1997) The evolution of sibling rivalry. Oxford University Press, Oxford

Radl RC, Linsenmair KE (1991) Maternal behaviour and nest recognition in the subsocial earwig Labidura riparia Pallas (Dermaptera: Labiduridae). Ethology 89:287-296

Sandrin L, Meunier J, Raveh S, Walser JC, Kölliker M (2015) Multiple paternity and mating group size in the European earwig, Forficula auricularia. Ecol Entomol 40:159-166

Trivers RL (1974) Parent-offspring conflict. Am Zool 14:249-264

Weyrauch WK (1927) Experimentelle Analyse der Brutpflege des Ohrwurmes Forficula auricularia L. Biol Zentralbl 49:553-558

Wong JWY, Kölliker M (2013) The more the merrier? Condition-dependent brood mixing in earwigs. Anim Behav 86:845-850

Wong JWY, Meunier J, Kölliker M (2013) The evolution of parental care in insects: the roles of ecology, lifehistory and the social environment. Ecol Entomol 38:123-137

Wong JWY, Lucas C, Kölliker M (2014a) Cues of maternal condition influence offspring selfishness. PLoS One 9, e87214

Wong JWY, Meunier J, Lucas C, Kölliker M (2014b) Paternal signature in kin recognition cues of a social insect: concealed in juveniles, revealed in adults. Proc R Soc Lond B 281:20141236 